\title{
Immersion, reflexivity and distraction: spatial strategies for digital cities
}

\section{Scott McQuire}

Immersion is an elusive and ambiguous quality. While, on the one hand, it denotes a state of heightened concentration, immersion can also constitute a form of forgetting. To be immersed in a book, for instance, suggests that identification with its diegetic world has become so intense that your capacity to relate to your immediate surroundings is diminished, perhaps to the point of oblivion. This hint of fervour arising from total occupation of the senses by one set of stimuli signals the religious roots of immersion (it is a synonym for baptism). It also indicates one reason why immersion is a quality that has been frequently associated with new generations of media. Because of their capacity to re-orient the senses and thereby re-invent existing bounds of time and space, new media have frequently been the subject of evangelistic desire.

This is not a recent phenomenon. For instance, in the $19^{\text {th }}$ century as the novel became increasingly popular, it was acclaimed and castigated precisely because of its capacity to submerge the minds of readers in imaginary worlds. However, it was the invention of cinema at the dawn of the $20^{\text {th }}$ century which created a new type of immersive experience. Building on popular $19^{\text {th }}$ century entertainment forms such as panoramic painting and the diorama, cinema created a general architecture for the production of ephemeral environments capable of displacing the surrounding world, at least for a time. Following cinema, immersion no longer referred primarily to a state of consciousness, such as religious ecstasy or pseudo-religious concentration, but increasingly arose from the technological capacity to project alternate worlds.

The full ambiguity of the cinematic displacement of the world - which forms one of the key thresholds of modern experience - is felt only by considering two related trajectories. One is the extent to which the image world constructed in cinema's interior space nevertheless borrows its clothes from the world outside. As Deleuze (1986: 37) put it (following the tracks of Merleau-Ponty): 'With the cinema, it is the world which becomes its own image, 
and not an image which becomes the world'. This is only partly a question of 'realism' in the traditional sense. While filming phenomena such as rippling water or eddying smoke conveyed a qualitatively different and unprecedented level of visual detail to eyes schooled by painting, cinema's most radical effect is not simply a function of the fact that things move inside its frame. Rather, it stems from the alignment of the spectator's eye with the camera itself. Identification with the cine-camera's mobile gaze became the prototype for all subsequent forms of modern technological vision; it enabled the construction of a new and, as Vertov rightly proclaimed, profoundly inhuman phenomenology with all the uncertainties this entails. As André Breton (1978: 8) observed in 1920:

Today, thanks to the cinema, we know how to make a locomotive arrive in a picture. As the use of slow and fast motion cameras becomes more general, as we grow accustomed to see oaks spring up and antelopes floating through the air, we begin to foresee with extreme emotion what this time-space of which people are talking might be. Soon the expression 'as far as the eye can reach' will seem to us devoid of meaning; that is, we shall perceive the passage from birth to death without so much as blinking, and we shall observe infinitesimal variations. As it is easy to see by applying this method to the study of a boxing match, the only mechanism it can possibly paralyse in us is that of suffering. Who knows whether we may not thus be preparing to escape one day from the principle of identity?

The circle of ambiguity which defines cinematic immersion closes with a second trajectory. At the same time that cinema reconstructs the phenomenal world for the decentred modern subject, the world at large becomes an increasingly technological environment. The displacement of nature by 'second nature' is exemplified by the rise of the city as the dominant lived environment. If Nature was once broadly conceived as God's script to be deciphered by religious (or later scientific) guidance, the constructed world of the modern city demanded new protocols. As Benjamin pointed out in the 1930s, the camera's mobile gaze converges in fundamental ways with the city's novel perceptual conditions characterised by the proliferation of artificial light, transparent and reflective surfaces, mechanical movement and the rapid juxtaposition of heterogeneous phenomena. The logic of this condition, which inspired Kittler's (1996) call to treat the city as a medium, not only becomes more apparent in the digital era, as media become cheaper, scalable, and ubiquitous, but registers a qualitative change, as urban space becomes a matrix of 'real time' feedback networks.

Historically, the cinema effect can be aligned with modern technologies of transportation. In displacing the co-ordinates of the local and the immediate, the question incessantly posed by 
cinematic immersion was 'where am I?' The peak of this trajectory is found in contemporary developments such as VR technology, and various 360 degree and largescreen formats such as IMAX and OMNIMAX. All share the common strategy of saturating the spectator's perceptual apparatus with the aim of triggering a different register of affect. Australia's most successful large-format film-maker John Weiley (1999) describes viewing the 3D brain-pattern images produced for his film Imagine:

It was fascinating and it taught me some basic things about the medium. Because one of the things we discovered was that showing people movies on a television screen and showing them print on a television screen or print on paper activated the same regions of the brain, engaged the same regions of the brain in comprehension. But as soon as we put on our VR goggles so that they have no frame of reference, the old areas of the brain, the sort of old reptilian brain was all brought into action - you know, the things that govern digestion and breathing and balance. They're all brought into play, they all became part of the experience which is highly relevant if you're working in the giant screen frameless medium.

As Weiley notes, immersive media foreground kinaesthetic and 'instinctual' bodily responses over the symbolic logic of print or small screen. The importance of narrative as a strategy for deciphering appearances is consequently diminished in favour of other pleasures, including the sensation of different forms of motion such as gliding and flying, and 'sublime' experiences such as shock and awe.

Ambiguity has always surrounded the relation between the 'real' and the 'virtual' in various forms of immersive media. In cinema, the two worlds were separated - in principle at least - by the threshold of entry and the various rites of passage (darkness, silence, immobilisation of the body) that 'going to the movies' entailed. In the $21^{\text {st }}$ century, as the extension of digital media throughout urban space produces an unprecedented intertwining of architectural and media space, establishing new forms of co-presence while undermining the certainty of older distinctions between inside and outside, a new sense of ambiguity pertains to immersion. For those dwelling in urban spaces saturated by digital media, immersive experiences are not only frequent and everyday — walking through the city at night wearing an iPod - but overlapping and multi-layered. Drawing on psychoanalysis, one might say immersion is a condition which has become overdetermined. This raises an intriguing question about immersive experiences in contemporary art: how do we know when we're in it? 
Questions of this ilk were posed by Rafael Lozano-Hemmer's light-based installation Homographies exhibited at the Art Gallery of New South Wales as part of the 2006 Sydney Biennale. ${ }^{1}$ Homographies continued Lozano-Hemmer's series of 'subscuplture' works in which a massed group of identical objects respond to the contingent movement of spectators by moving themselves. Whereas Lozano-Hemmer had previously used everyday items such as bottles and belts, here the performers of his ballet mécanique were 144 fluorescent lights arrayed in a conventional modernist grid. Distributed at ceiling level above the gallery's main entrance court, the lights were mounted on moveable fixtures controlled by computerized surveillance systems. Seven cameras tracked the movement of visitors through the entrance court, triggering the rotation of the individual light tubes. A series of plasma screens along one wall showed visitors seen from the perspective of the tracking system overlaid with positional data.

The work involves two main concerns. One, which is never far from contemporary interactive art, is surveillance. The ambivalence surrounding digital media in the present is measured precisely by its implication in contemporary developments to 'secure' public space through what Lyon (2001) calls 'surveillant sorting'. Yet new media technologies also offer tantalising glimpses of more participatory and inclusive forms of mediated public space. If media technologies have historically been integrated into the spatial dynamics of the city along dominant axes of commodity spectacle and surveillance, the extent to which contemporary media might be used to promote other forms of spatial agency remains a critical issue. Lozano-Hemmer (2005: 4) argues: 'I have no doubt that a new type of art is emerging in order to confront these technologies of the panoptic and post-optic gaze. The Institute for Applied Autonomy, Harun Farocki and the Bureau of Inverse Technology are some examples of this new line of inquiry'. Lozano-Hemmer's own work might also be situated in this lineage. For example, his Subtitled Public used a computerized surveillance system to track visitors to the exhibition space, projecting randomly selected words onto their bodies. The visitor cannot 'get rid' of the word, unless they happen to make contact with another visitor, in which case the words are swapped between them. The point of the work is not simply to render the fact of surveillance visible - this is so commonplace that it defines to popular culture scenarios exemplified by the global franchise of Big Brother-but rather to open the surveillance logic of assigning names and identities, often in a most arbitrary fashion, to critical scrutiny.

\footnotetext{
${ }^{1}$ Homographies was produced with the assistance of Conroy Badger, Matt Biederman, Sandra
} Badger, Natalie Bouchard and Will Bauer. 
The other main ambition of Homographies is complexity. More specifically, Homographies addresses the problem of how we might visualize complex patterns and non-linear forms of causality. Lozano-Hemmer (2005: 12) argues:

\begin{abstract}
Recursive algorithms, chaos theory, cellular automata, digital genetics and other descriptions of complex dynamic processes are fascinating because they appear to be alive, to have life. Some exhibit evolution, others morphogenesis, and still others management and self-control. [...]. If during the Renaissance perspective and Fibonacci's series were used as media to legitimize the production of representation, today we can and should make dynamic mathematics our media. The Renaissance subject emerges precisely from the privileged vision of the vanishing point. What might be the equivalent impact as we contemplate, say, a fractal pattern?
\end{abstract}

Fractals arose from the attempt to visualize complex non-geometric phenomena such as clouds and coastlines, as well as processes such as neuronal connections, genetic mutations, and the variegation of leaves. To this list of natural phenomena, one could add the complex movement of people in public spaces. Lozano-Hemmer's 'subsculptures' challenge the organization of classical perspectival space, displacing the logic of the architectural 'vanishing point' and its correlate, the detached and seemingly omniscient viewer, with what he calls 'connective' aesthetics. In Homographies, the presence of a single person within the light-space is registered by the light-tubes as if they are iron filings pulled to and fro by the shifting magnetic force of human presence. Responding to two or more visitors, the work produces what Lozano-Hemmer describes as 'light-corridors' connecting them in a field. At regular periodic interludes the work returns to 'zero' as all the lights are automatically aligned into random orthogonal patterns. The effect of the work is to shift focus from individual patterns to the movement between them. Like isobars mapping shifts in barometric pressure, the continual movements produce ephemeral constellations which are neither random nor yet entirely predictable. The result is the displacement of the stasis of the modernist grid in favour of a subtle spatial flux. Lozano-Hemmer (2005: 10) notes:

I don't yet have a definition of what 'Subsculpture' is but I think it has to do with contagion matrices. All of the installations consist of two or more interconnected robotic or virtual entities. The rules of behavior for these entities are relatively simple, but they are dependent on and influenced by the status of neighbouring entities or other inputs, for example the surveillance of the public (my installations almost always 'watch the watchers', as Daniel Garcia Andújar would say). In this way, they achieve an unpredictable and emergent global behavior, where turbulence and other phenomena that are products of non-linear processes are found. 
If non-linear causality can be understood as an attempt by science to reconceptualize apparently random phenomena, this undertaking has been paralleled by the increasing importance that contingency and chance has assumed in modern and contemporary art. The role of the audience as the site of the work's production, elevated by Duchamp (1957) into the 'art coefficient', takes on growing significance in the context of digital culture. For Lozano-Hemmmer (2005: 5) digital media raise new possibilities of 'programming without teleology'.

By means of non-linear mathematics, like cellular automata, probabilistic ramifications, recursive algorithms or chaos strategies it's possible to write programs whose results will surprise the author. That's to say the machine can have certain autonomy and expression because you simply capture initial 'algorithmic conditions' but do not preprogram the outcome. This for me is a gratifying post-humanist message, a message that invites humility, but also one that marks a crisis in authorship and opens a wide problematic area, and I say 'welcome!' to that.

Surprise can take many forms. In an earlier project (Re: Positioning Fear staged at Graz in 1993) Lozano-Hemmer (2005: 6) recalls his assumption that the shadows generated by this large-scale projective work would function as metaphors for fear:

I was totally wrong! As soon as people passed by and noticed the installation they would start to play with their shadows and perform humorous pantomimes. The huge dimension of the shadows allowed, for example, for school children to step on their teachers, or that a man in a wheelchair could roll his twenty-five-meter-high shadow over the others deriving great pleasure from squashing them with his giant wheels. The installation was converted into an ad hoc carnival and nobody thought for one minute about fears, plagues or invasions. This was one of the most entertaining errors of my career.

Homographies perhaps took a similar step into unexpected territory. Lozano-Hemmer has previously worked with light as a primary element of interactive art, notably in Vectorial Elevation first staged in Mexico City's famed Zócalo Plaza. But where Vectorial Elevation created a highly visible, user-configured architecture of light, Homographies occupied a quite different register. As I sat watching, I was struck by how few visitors to the gallery seemed to really notice the work. People stood under the lights, sometimes for minutes at a time as they met others or looked at other works (including the plasma screens) hung around 
the walls. Frequently, they left without seeing the lights. ${ }^{2}$ This was not because the lights were hidden - all visitors had to do was look up to encounter the uncanny sight of rows of fluoro tubes revolving silently above their heads. But, as Poe reminds us in The Purloined Letter, the best place to hide something can be precisely where you might expect to see it. Placing an artwork made of lights on a ceiling effectively rendered them, not so much invisible, but shielded by their very obviousness. In a context in which focus is conventionally directed towards the walls, lighting retreats to the background. The fact that light is the condition for the visibility of other objects masks its own existence.

Does this mean that the work 'failed'? I find this a particularly interesting question. On the one hand, I suspect the fact that so many visitors seemed oblivious to key aspects of the work was unexpected. Personally, I was astounded that most people remained seemingly unaware of the light-tubes whirring around above them. On the other hand, the fact that people didn't focus on the work doesn't necessarily mean it had no effect. Rather, it suggests that the work was consumed in a distracted fashion. As Benjamin argued, distracted perception rather than focused attention is precisely the mode in which architecture is conventionally consumed.

Does it make sense to speak of 'distracted' immersion? If Homographies constructed an immersive space, it was certainly not according to the totalising model of VR in which technological intensification attempts to occupy the senses. It was not even as 'total' as the detailed material simulations of alternate worlds which characterize some examples of installation art, nor yet as total as the themed 'entertainment architecture' pioneered by Disney, for that matter. Rather, the work modified an existing environment, merging art with the everyday in a gesture which owes more to groups such as Fluxus and the Situationists. Nevertheless, the fact that Homographies uses light as its primary element produces an affinity with immersive art works. It is common to speak of being bathed in light. Light's fluid qualities which can be actively used to delineate space and to define its ambiance creates a secular, technological version of something like the older (baptismal) sense of immersion. Homographies is immersive in the sense that it constitutes an environment according to the manner that McLuhan categorised media as environments. In expanding immersion in this way, does the term lose its meaning? If the immersed spectator has always been on the edge of distraction, what are the possibilities of utilising distraction to radical ends in the era of reflexive modernity?

2 This can be seen on the video of Homographies at http://www.lozanohemmer.com/video/homograpiesedit2.mov. 
In this respect, it is worth remembering that Benjamin's rationale for the radicality of cinema relied on the fact that, like architecture, it was consumed in distraction. ${ }^{3}$ Seduced by their ostensible focus on stories and stars, film audiences also ingested new urban ensembles in a distracted fashion - the city became a montage of fragments, juxtapositions, and speeds which Benjamin hoped might coalesce into an image of the complex patterns of modern life. Benjamin's counter-intuitive move was to argue that, insofar as reception could be removed from conscious attention, there would be a corresponding decline in the efficiency of the habitual 'stimulus shield' that urban dwellers developed to compensate for the continual shocks experienced in big city life. In other words, it was necessary to subvert the 'filter' of consciousness in order to confront the new realities of urban industrial life. Borrowing from Freud and Simmel, Benjamin argued that habituation to shock enabled consciousness to 'screen' external stimulation by locating it in a unilinear chain according to the historicist model of temporality. As a result, rather than entering 'long experience' in which individual memory and the collective past are intermingled, such stimulation is reduced to the sort of isolated individual experiences that Simmel described as intellectualism, or more ominously, the blasé attitude. However, to the extent that the stimulus shield of habitual perception could be eluded, individual experience could potentially be reconnected to collective history. At least for a time, Benjamin imagined this might occur via the 'optical unconscious' created by cinema.

Most subsequent avant-garde cinema eschewed Benjaminian distraction in favour of a Brechtian aesthetic of 'reflexive' spectatorship. The influential strategy adopted by Godard in the 1960s, for example, consistently stressed the need to puncture narrative film's immersive qualities by emphasizing its material and constructed nature. However, such reflexivity has its limits. In the contemporary context of knowingly ironic media texts, new tactics are called for. Moreover, as cities become environments in which the 'immersive' qualities of architecture are increasingly intermingled with media space, and art is increasingly intermingled with everyday life, new ways of thinking about immersion are necessary.

\footnotetext{
${ }^{3}$ Benjamin (2003: 269) argued: 'Reception in distraction - the sort of reception which is increasingly noticeable in all areas of art and is a symptom of profound changes in apperception-finds in film its true training ground. Film, by virtue of its shock effects, is predisposed to this form of reception. It makes cult value recede into the background, not only because it encourages an evaluating attitude in the audience but also because, at the movies, the evaluating attitude requires no attention. The audience is an examiner but a distracted one'.
} 
Homographies probes these lines. It suggests that dwelling in the modern world especially but not exclusively urban and technological environments - demands new forms of inhabiting space and new relations to technology. It embodies a profoundly antiCartesian stance. Whereas Descartes (one inaugurator of the 'grid') began from the radical presumption of the subject's separation from the world as object, inaugurating what Heidegger calls the modern age of the world picture, Homographies presumes not a Cartesian space with fixed co-ordinates delineating inside and outside, but the ambiguity of a mutable space with multiple and heterogeneous dimensions in which we are irretrievably imbricated. If classical phenomenology treated 'being in the world' as a form of immersion-Heidegger, for example, famously describes dasein as 'thrown' into the world - for those such as Latour who want to extend the phenomenological project into a post-humanist phase, it is precisely the conditions of our immersion in a technological world which must be explored. The complex patterns that Homographies sketched above the heads of its human participants, both reflexive and distracted, play a part in this project.

(C) Scott McQuire December 2006. 


\section{References}

Breton, A. (1978 ) 'Max Ernst' in Rosemount, F. (ed.), What Is Surrealism?, London, Pluto Press.

Deleuze, G. (1986) Cinema 1: The Movement-Image (trans. H. Tomlinson \& B. Hammerjam), London, The Athlone Press.

Duchamp, M. (1957) 'The Creative Act' in Sanouillet. M. and Peterson, E. (eds.) (1975) Salt Seller: The Essential Writings of Marcel Duchamp (Marchand du Sel), London, Thames and Hudson.

Kittler, F. (1996) The City is a Medium, New Literary History. 27(4): 717-729.

Merleau-Ponty, M. (1964) 'The Film and the New Psychology' in Sense and Non-Sense (trans. H.L. \& P.A. Dreyfus), Evantson, Ill., Northwestern University Press (first published 1945)

Lozano-Hemmer, R. (2005) Interview by José Luis Barrios, published in the Subsculptures catalog by Gallery Guy Bärtschi, Switzerland (English translation by Rebecca MacSween). Available online at http://www.lozano-hemmer.com/ecomisario.html

Lyon D. (2001) Surveillance Society: Monitoring Everyday Life, Philadelphia, Open University.

Weiley, J. (1999) Interview with the author, Byron Bay, NSW. 


\section{University Library}

\section{- M M I E E R VA A gateway to Melbourne's research publications}

Minerva Access is the Institutional Repository of The University of Melbourne

Author/s:

MCQUIRE, S.

Title:

Immersion, reflexivity and distraction: spatial strategies for digital cities

Date:

2007

Citation:

McQuire, S. (2007). Immersion, reflexivity and distraction: spatial strategies for digital cities.

Visual Communication, June, 6(2), 146-155.

Publication Status:

Published

Persistent Link:

http://hdl.handle.net/11343/35077 